\title{
Depersonalization Disorder: Effects of Caffeine and Response to Pharmacotherapy
}

\author{
Murray B. Stein and Thomas W. Uhde
}

\section{Introduction}

The symptoms of depersonalization and derealization have been reported across a wide spectrum of psychiatric disorders. These include schizophrenia (Lehmann and Cancro 1985), borderline personality disorder (Cowdry et al. 1985; Chopra and Beatson 1986), panic disorder (Boulenger et al. 1986; Stein and Uhde 1989), and of course, the dissociative disorders, such as multiple personality disorder (Putnam et al. 1986). As an isolated disorder, the syndrome of chronic depersonalization and derealization is believed to be rare (Nemiah 1985). DSM-IIIR refers to this syndrome as "depersonalization disorder" and has placed it under the classification of "dissociative disorders."

Although very little is known about the course of depersonalization disorder, it is believed to start most commonly in adolescence or early adulthood, to begin abruptly, to become chronic in the majority of cases, and to be resistant to treatment (Nemiah 1985). Though intrapsychic processes have been most frequently implicated as a mechanism for depersonalization (Levy and Wachtel 1978), biological factors may also be important, but have been relatively unexplored to date (Noyes et al. 1987). Depersonalization can occur as a symptom of temporal lobe dysfunction (Gloor et al. 1982; Ghadirian et al. 1986) or as an adverse effect of various medications, such as indomethacin (Schwartz and Moura 1983). Depersonalization may also occur following marijuana use (Moran 1986) and may become chronic in some of these cases (Szymansky 1981; Keshaven and Lishman 1986). There is thus ample rationale to explore the role of biological factors in this disorder.

In this article, we describe a detailed psychobiological investigation of a single patient with depersonalization disorder. The patient participated in single-blind therapeutic trials of carbamazepine and clonazepam and also took part in a caffeine challenge paradigm. The latter was conducted to explore our hypothesis that depersonalization disorder might share a common pathophysiology with panic disorder, a syndrome known to be exacerbated by caffeine administration (Boulenger et al. 1984; Charney et al. 1985; Uhde and Boulenger 1988).

\section{Case Report}

The patient studied was a 28-year-old married woman with a 6-year history of chronic depersonalization and derealization. Her symptoms began abruptly one morning while

From the Unit on Anxiety and Affective Disorders, Biological Psychiatry Branch, National Institute of Mental Health, Bethesda, MD

Address reprint requests to Dr. Thomas W. Uhde. Building 10, Room 3S239, 9000 Rockville Pike, Bethesda, MD 20892. Received September 17, 1988; revised November 8, 1988. 


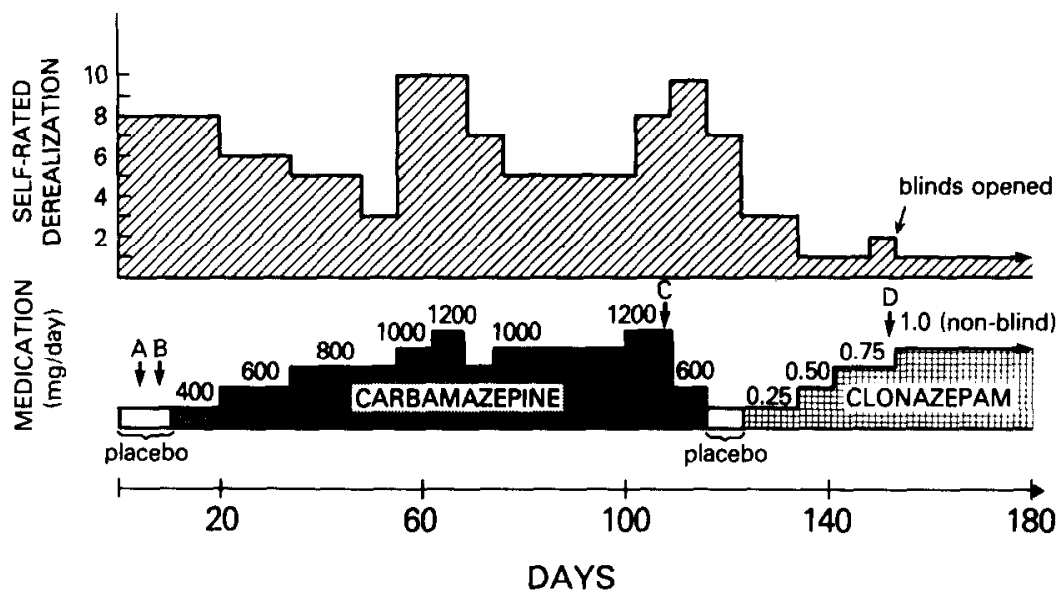

Figure 1. Course of treatment of a patient with depersonalization disorder (A) Placebo administered; (B) $240 \mathrm{mg}$ caffeine administered while on placebo; (C) $240 \mathrm{mg}$ caffeine administered while on $1200 \mathrm{mg}$ of carbamazepine/day; (D) $240 \mathrm{mg}$ caffeine administered while on $0.75 \mathrm{mg}$ of clonazepam per day.

she was a senior in college at age 22 and under no readily identifiable stressor. Her symptoms consisted of the constant feeling "like I'm looking in on a conversation and not participating," accompanied by the feeling of being in a "fog" and associated with the symptom of "dizziness." The patient also complained of chronic problems with her concentration and memory, which she attributed to feeling "out of touch" with her surroundings. She described a pattern of diurnal variation to her symptoms, being typically more severe in the morning.

Historically, the patient described a happy childhood and denied any experiences of physical or sexual abuse. She had always been a social, outgoing individual, without any evidence of overt premorbid psychopathology. At the time of assessment, she had been married for 3 years, and had a 10-month-old daughter; interestingly, she reported a postpartum exacerbation of her symptoms. Also of interest, the patient's mother was currently in treatment with another psychiatrist for panic disorder and was reportedly doing well on a combination of amitriptyline and clonazepam.

The patient was assessed using a semistructured interview derived from the Schedule for Affective Disorders and Schizophrenia-Lifetime version (SADS-L) to allow the formulation of DSM-IIIR lifetime diagnoses. She met current diagnostic criteria for depersonalization disorder and had no other lifetime psychiatric diagnosis, including any affective, anxiety, or other dissociative disorder. Laboratory testing revealed a normal complete blood count (CBC), SMA-20, and thyroid function indices. A sleep-deprived electroencephalogram (EEG) with nasopharyngeal leads was normal, as were a computerized tomogram of the cerebrum and magnetic resonance image (MRI) of the posterior fossa (in view of the complaint of dizziness).

The patient's clinical response to single-blind trials of carbamazepine and clonazepam is shown in Figure 1. Although a transient initial response to carbamazepine could be seen in the patient's global self-rating of depersonalization/derealization symptoms, this was not sustained, despite increases in dosage to $1200 \mathrm{mg} /$ day (with carbamazepine blood level of $6.2 \mu \mathrm{g} / \mathrm{ml}$ ). Interestingly, however, the patient experienced an exacerbation of symptoms when her carbamazepine dose was abruptly reduced from 1200 to $600 \mathrm{mg} /$ day, 


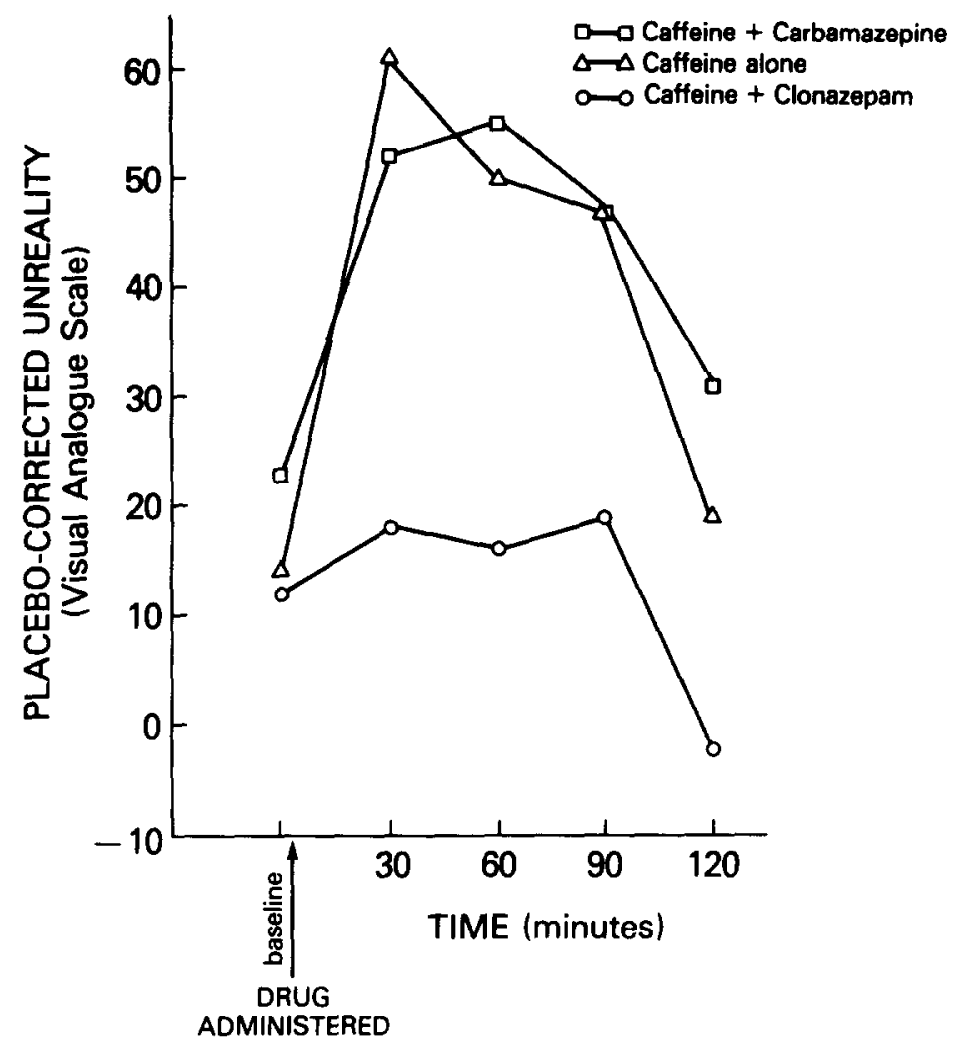

Figure 2. The increase in derealization in response to caffeine administration $(240 \mathrm{mg})$ is attenuated by clonazepam but not by carbamazepine.

and she had two spontaneous panic attacks (which she had never experienced before). When clonazepam was instituted, a prompt reduction in symptoms occurred. For the first time in nearly 6 years, the patient described feeling nearly free of her depersonalization/derealization symptoms.

The patient also gave her informed, written consent to the blind administration of oral caffeine $(240 \mathrm{mg}$ ) and/or placebo as part of a challenge paradigm to study her symptoms in our laboratory. These challenges were conducted at various phases in her treatment, as indicated in Figure 1. It can be seen that caffeine resulted in a robust increase in selfrated derealization (as measured by visual analog scale), which was significantly attenuated by chronic clonazepam treatment, but not by chronic carbamazepine treatment (Figure 2).

\section{Discussion}

In this report, we have illustrated the case of an individual with depersonalization disorder whose symptoms were exacerbated by caffeine administration and responded to pharmacological therapy. Although the findings from a single case must be interpreted cautiously, we believe that some interesting hypotheses may be generated from these observations.

The relatively limited literature to date on depersonalization disorder has focused 
primarily on psychotherapeutic approaches to treatment (Torch 1987). It has recently been suggested that the tricyclic antidepressant desipramine may be a possible treatment for depersonalization disorder (Noyes et al. 1987). Our experience in the treatment of the patient we have described suggests that the benzodiazepine anticonvulsant clonazepam may have a role to play in this disorder. Although we initially chose the anticonvulsants carbamazepine and clonazepam as potential treatments because of the clinical links between the experience of depersonalization/derealization and temporal lobe epilepsy (Gloor et al. 1982), it is intriguing to note that clonazepam proved effective, whereas carbamazepine did not. This parallels our experience and that of others in the treatment of panic disorder, where potent benzodiazepines are efficacious (Spier et al. 1986; Ballenger et al. 1988), and carbamazepine is considerably less efficacious in most patients (Uhde et al. 1988). Of interest, this might suggest the preferential importance of central-type benzodiazepine receptors over peripheral-type benzodiazepine receptors (Weiss et al. 1985 ) in the pathogenesis and treatment of depersonalization disorder. However, in view of this being a single case report, these speculations remain tentative.

We believe that our observations suggest that depersonalization disorder, or perhaps a subset of this disorder, may more rightfully belong in the class of "anxiety disorders," rather than "dissociative disorders." Several factors point us toward this conclusion.

First, the symptoms of depersonalization and derealization are extremely common as prominant complaints in patients with panic disorder (Uhde et al. 1985; Boulenger et al. 1986; Stein and Uhde 1989). In fact, Sir Martin Roth originally referred to it as the "phobic anxiety-depersonalization syndrome" (Roth 1959). Second, the suggestion that some cases of depersonalization disorder may respond to treatment with tricyclics or high-potency benzodiazepines is consistent with the response pattern for panic disorder. Third, our patient's symptom exacerbation in response to caffeine is consistent with the experience of patients with panic disorder (Boulenger et al. 1984; Charney et al. 1985; Uhde and Boulenger 1988). This response to caffeine, however, has not been well studied in other psychiatric disorders, and therefore, may not be specific for panic or anxiety disorders. The response of subjects with depersonalization disorder to lactate administration, a known anxiogenic stimulus in panic disorder (Liebowitz et al. 1983), would be of great theoretical interest in this regard. Fourth, our patient's first-degree family history of panic disorder (her mother) and response to clonazepam suggest that a shared heritability for panic and depersonalization may exist; again, this remains as an intriguing supposition at the present time.

Other authors (Obendorf 1950; Brauer et al. 1970; Noyes et al. 1987) have also posited a close relationship between anxiety and depersonalization disorder. Others (Ross and Anderson 1988) have recently noted an overlap in phenomena betwecn obsessive-compulsive disorder and multiple personality disorder, thereby reinforcing our impression that a close relationship between the dissociative disorders and the anxiety disorders may exist in some cases.

This report is not intended to suggest that intrapsychic or psychosocial factors are unimportant in depersonalization disorder. On the contrary, stressful life situations have been associated with the exacerbation of panic disorder (Roy-Byrne et al. 1986a,b), and events such as work pressures were clearly seen to cause a worsening of the patient's symptomatology in the case described here. Nonetheless, our observations allow us to propose that biological factors, heretofore relatively neglected in the literature, may also play an important role in this disorder. In some individuals, there may exist a physiological predisposition to the so-called "dissociative" experience of depersonalization/ 
derealization. This is a hypothesis deserving of additional consideration and study. Furthermore, controlled drug trials should be undertaken for the treatment of this chronic, often disabling, disorder.

We thank Marilla Geraci, B.S.N., and Diana Roscow for their assistance and Janis Thurman for preparation of this manuscript.

\section{References}

Ballenger JC, Burrows GD, Dupont RL Jr, Lesser IM, Noyes R Jr, Pecknold JC, Rifkin A, Swinson RP (1988): Alprazolam in panic disorder and agoraphobia: Results from a multicenter trial. I. Efficacy in short-term treatment. Arch Gen Psychiatry 45:413-422.

Boulenger J-P, Uhde TW, Wolff EA, et al (1984): Increased sensitivity to caffeine in patients with panic disorder: Preliminary evidence. Arch Gen Psychiatry 41:1067-1071.

Boulenger J-P, Bierer LM, Uhde TW, Silberman EK, Post RM (1986): Psychosensory phenomena in panic and affective disorders. In Shagass C, et al (ed), Biological Psychiatry 1985. New York: Elsevier Science.

Brauer R, Harrow M, Tucker GH (1970): Depersonalization phenomena in psychiatric patients. Br J Psychiatry 117:509-515.

Charney DS, Heninger GR, Jatlow PI (1985): Increased anxiogenic effects of caffeine in panic disorders. Arch Gen Psychiatry 42:233-243.

Chopra HD, Beatson JA (1986): Psychotic symptoms in borderline personality disorder. Am $J$ Psychiatry 143:1605-1607.

Cowdry RW, Pickar D, Davies R (1985): Symptoms and EEG findings in the borderline syndrome. Int J Psychiatry Med 15:201-211.

Ghadirian AM, Gauthier S, Bertrand S (1986): Anxiety attacks in a patient with a right temporal lobe meningioma. J Clin Psychiatry 47:270-271.

Gloor P, Olivier A, Quesney LF, Andermann F, Horowitz S (1982): The role of the limbic system in experiential phenomena of temporal lobe epilepsy. Ann Neurol 12:129-144.

Keshaven MS, Lishman WA (1986): Prolonged depersonalization following cannabis abuse (letter). Br J Addict 81:140-142.

Lehmann HE, Cancro R (1985): Schizophrenia: Clinical features. In Kaplan HI, Sadock BJ (eds), Comprehensive Textbook of Psychiatry (ed 4). Baltimore: Williams \& Wilkins, pp 680-713.

Levy JS, Wachtel PL (1978): Depersonalization: An effort at clarification. Am J Psychoanal 38:291300 .

Liebowitz M, Fyer A, Appleby I, et al (1983): Lactate provocation of panic attacks. Psychopharmacol Bull 19:476-478.

Moran C (1986): Depersonalization and agoraphobia associated with marijuana use. Br $J$ Med Psychol 59:187-196.

Nemiah JC (1985): Depersonalization disorder. In Kaplan HI, Sadock BJ (eds), Comprehensive Textbook of Psychiatry (ed 4). Baltimore: Williams \& Wilkins, pp 952-956.

Noyes R Jr, Kuperman S, Olson SB (1987): Desipramine: A possible treatment for depersonalization disorder. Can J Psychiatry 32:782-784.

Obendorf CP (1950): The role of anxiety in depersonalization. Int J Psychoanal 31:1-5.

Putnam FW, Guroff JJ, Silberman EK, et al (1986): The clinical phenomenology of multiple personality disorder: Review of 100 recent cases. J CLin Psychiatry 47:285-293.

Ross CA, Anderson G (1988): Phenomenological overlap of multiple personality disorder and obsessive-compulsive disorder. J Nerv Ment Dis 176:295-299.

Roth M (1959): The phobic anxiety-depersonalization syndrome. J R Soc Med 52:587. 
Roy-Byrne PP, Geraci M, Uhde TW (1986a): Life events and the onset of panic disorder. Am J Psychiatry 143:1424-1427.

Roy-Byrne PP, Geraci M, Uhde TW (1986b): Life events and course of illness in patients with panic disorder. Am J Psychiatry 143:1033-1035.

Schwartz JI, Moura RJ (1983): Severe depersonalization and anxiety associated with indomethacin. South Med J 76:679-680.

Spier SA, Tesar GE, Rosenbaum JF, Woods SW (1986): Treatment of panic disorder and agoraphobia with clonazepam. $J$ Clin Psychiatry 47:238-242.

Stein MB, Uhde TW (1989): Infrequent occurrence of EEG abnormalities in panic disorder. Am $J$ Psychiatry (in press).

Szymansky HV (1981): Prolonged depersonalization after marijuana use. Am J Psychiatry 138:251253.

Torch EM (1987): The psychotherapeutic treatment of depersonalization disorder. Hillside J Clin Psychiatry 9:133-151.

Uhde TW, Boulenger J-P (1988): Caffeine model of panic. In Lerer B, Gershon S (eds), New Directions in Affective Disorders. New York: Springer-Verlag.

Uhde TW, Boulenger J-P, Roy-Byrne PP, Geraci MF, Vittone BJ, Post RM (1985): Longitudinal course of panic disorder: Clinical and biological considerations. Prog Neuropsychopharmacol Biol Psychiatry 9:39-51.

Uhde TW, Stein MB, Post RM (1988): Lack of efficacy of carbamazepine in the treatment of panic disorder. Am J Psychiatry 145:1104-1109.

Weiss SRB, Post RM, Patel J, et al (1985): Differential mediation of the anticonvulsant effects of carbamazepine and diazepam. Life Sri 36:2413-2419. 